\title{
A New Market Segmentation Approach: Evidence from Two Canadian Cities
}

\author{
Dea van Lierop and Ahmed El-Geneidy \\ McGill University
}

\begin{abstract}
Traditionally, transit market research has categorized passengers into two distinct groups: captive riders and choice riders. Market analyses that depend on such broad categories are likely to overlook important details about the needs and desires of their customer base. This study attempts to better understand the complexities of the different groups who take transit by using information from five years of customer satisfaction questionnaires collected by two Canadian transit providers. Employing a series of clustering techniques, the analysis reveals that nine market segments are present across different modes in both transit agencies. Three different overarching groups of transit users are identified based on income and vehicle access: choice users ( 69\%), captive users ( 18\%), and captive-by-choice users ( 13\%). The groups are consistent across transit modes and in different geographical regions and are generalizable enough to be widely applicable as a conceptual framework for segmenting and understanding public transit users.
\end{abstract}

Keywords: Transit market, market segmentation, captive user, choice user, mode choice

\section{Introduction}

Although transportation agencies and public policymakers have brought attention to the importance of increasing transit mode share, transit usage still lags significantly behind that of the car. Thus, to increase ridership, transit agencies and governments first need to understand what motivates individuals to use environmentally- and sociallysustainable forms of transportation such as public transit. Although much research attempts to elucidate what motivates drivers to switch to taking transit (Abou-Zeidet al. 2012; Curtis and Headicar 1997), fewer studies attempt to understand how to maintain and increase ridership among existing transit users. It is important for transit agencies to focus on retaining existing users, as it is known that individuals stop using transit for many reasons, including changes in income, family size, the availability of another mode, 
as well as reasons related to the quality of service (Evans 2004; Grimsrud and El-Geneidy 2014; Perk et al. 2008).

One way to motivate existing users to remain loyal to the transit system is through increasing their satisfaction by taking into account their needs, perceptions, and desires with respect to transit. It is important to understand how to motivate loyalty in transit as it "involves a commitment on the part of the customer to make a sustained investment in an ongoing relationship with transit service" (Transportation Research Board 1999, 18). However, before developing strategies that attempt to increase satisfaction and loyalty among current transit users, it is beneficial to segment the market. Traditionally, transit market research has categorized riders into two distinct groups: captive riders and choice riders. Captive transit riders are commonly defined as individuals who do not have an alternative transportation choice; choice riders are those who choose to use transit even though another mode, such as a car, is available to them (Beimborn et al. 2003; Jacques et al. 2013; Krizek and El-Geneidy 2007; Wilson et al. 1984). Although it is important for transit agencies to acknowledge the presence of these two groups, analyses that depend on these broad categories are likely to overlook details about the needs and desires of their customer base. Therefore, rather than taking an approach to market segmentation that relies only on an analysis of whether or not transit users have access to alternative modes, the present study attempts to better understand the complexities of different groups who use transit. This is executed by using information about transit user socioeconomic status, personal preferences, and perceptions of satisfaction with transit services.

Nearly a decade ago, Krizek and El-Geneidy (2007) identified the habits and preferences of captive and choice transit users. Since then, transit markets have changed and new groups have emerged; Figure 1 demonstrates their conceptual framework. This study uses their transit market segmentation as a base on which to expand knowledge about transit user markets. The purpose of this study is to expand the left side of Krizek and El-Geneidy's (2007) framework by assessing the different types of current transit users present in the two geographically-distinct Canadian cities of Montreal and Vancouver and update their transit market segmentation model.

FIGURE 1. Krizek and El-Geneidy's 2007 Current and Potential Transit Market

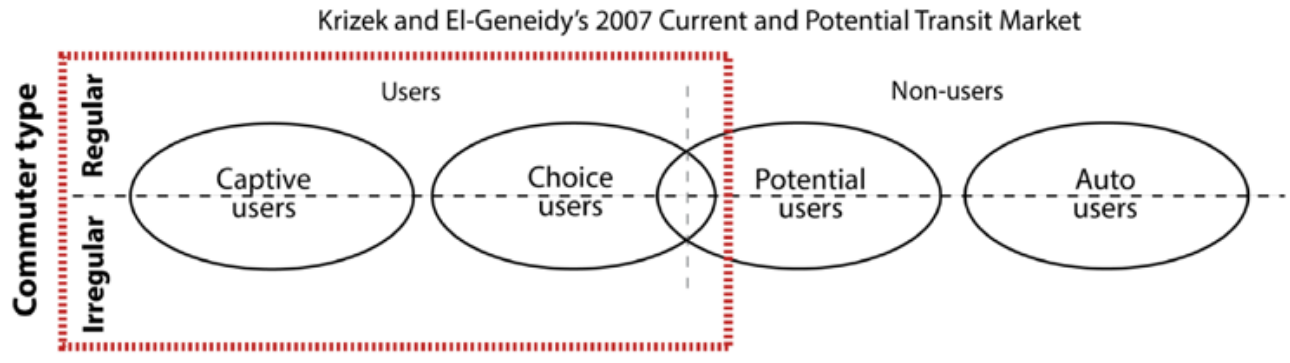

This paper begins with a review of the relevant literature related to market segmentation. Next, based on an analysis of customer surveys collected by transit agencies in both cities over a five-year period, statistical clustering techniques are used to uncover market segments that are consistent in both geographic contexts. This is followed by a discussion of policy recommendations aimed at increasing ridership 
among the different clusters. In doing so, this paper illustrates how already-existing data can be used productively to inform public transit research, policy, and managerial practice.

\section{Literature Review}

\section{Market Segmentation}

Transit agencies are showing growing interest in understanding consumer behavior and have recognized that market-orientated research in public transit is likely to result in increases in user satisfaction (Molander et al. 2012; Transportation Research Board 1998a, 1998b). A first step toward identifying ways to increase customer satisfaction is to develop a market segmentation strategy to understand the needs and desires of the different groups using transit. Whereas market segmentation analysis can be a difficult task for practitioners (Palmer and Millier 2004), it can serve as a research base on which other marketing strategies can be built (Weinstein 2004).

Within the field of transportation planning, there have been a limited number of studies assessing transit market segments. One of the earliest examples of grouping types of transit users is the Transportation Research Board's report on customer satisfaction (1999), which made suggestions for developing analyses that group current transit users as "secure," "favorable," "vulnerable," and "at risk" to accordingly develop appropriate marketing strategies.

Several empirical studies have attempted to segment the transit markets in various regions (Anable 2005; Beirão and Cabral 2008; Jensen 1999). For example, Beirão and Cabral (2008) determined six unique traveler segments with different attitudes, demographic profiles, and intentions for using public transit in Porto, Portugal. Furthermore, Wilson et al. (1984) developed four market segments to account for variation in choice and captive riders, and McLaughlin and Boyle (1997) identified transit-dependent populations in Los Angeles County by segmenting based on car availability and income. Beimborn and Greenwald (2003) segmented the transportation market in Portland, Oregon, into what they call choice and captive riders based on mode preference and mode options. These authors recommended that transit agencies use these categories to improve forecasting and service design. Based on this study, Krizek and El-Geneidy (2007) evaluated the habit and preferences of users and non-users of transit to segment the market in the Minneapolis-St. Paul, Minnesota, metropolitan area. They found eight different segments of transit users and non-users including captive and choice users and recommended that policies should be based on an understanding of commuter attitudes and preferences, emphasizing that the retention of current riders is as important as the attraction of new ones. Jacques et al. (2013) took the concept of choice vs. captive riders further and found four segments that they claim are more representative of the market: "convenience," which describes choice riders; "true captivity," which describes captive riders; and "utilitarian" and "dedication," which are neither clearly captive or choice riders. These authors suggested 
that segments should not be viewed as static groups, but that individuals can move between categories.

Most of the abovementioned studies were derived from a sample of transit users or non-users residing within one region and were based on convenience samples. The present study segments the transit market to avoid analyzing heterogeneous groups within a transit market. It adds to the literature by using a segmentation technique that identifies context-specific clusters, and then groups the identified clusters based on income and car access. Therefore, this study provides a nuanced approach to understanding current transit users that is generalizable enough to be widely applicable as a conceptual framework for segmenting and understanding public transit users. The findings can provide transit agencies with information necessary to better understand the needs and desires of different groups within a transit market (Demby 1994; Peter and Olson 1999; Weinstein 2004).

\section{Data}

The data used for this study were obtained from two large public transit agencies in Canada: Montreal's Société de transport de Montréal (STM) and Vancouver's TransLink under a data sharing agreement to be used in academic research. In 2011, the population of the Montreal census metropolitan area (CMA) was 3.8 million with a transit mode share of $22.2 \%$ for work trips. In Vancouver, the CMA population was 2.3 million with 19.7\% using transit for work trips (Statistics Canada 2014). The transit agencies in both cities provided the results of five years of customer satisfaction questionnaires that were conducted three or four times per year using telephone interviews. Telephone numbers were selected randomly, and respondents were filtered based on whether or not they use public transit. Only public transit users were interviewed and included in the sample. (Because participation was voluntary, non-response bias may be present.) In both Montreal and Vancouver, these routine questionnaires are intended to evaluate the quality of the transit service provided by the transit agencies and are used by the transit agencies to better understand perception of service quality and also as insight into where changes and/or improvements to service attributes could be accomplished to increase customer satisfaction and, accordingly, increase overall ridership.

To assess customer satisfaction with the transit service, the STM asks survey participants to report their experience with transit in general over the last 30 days. TransLink, however, takes a different approach by asking participants to specifically report their experience on their last and second-to-last trip. Although both strategies are appropriate for collecting information concerning customer satisfaction, the STM's approach to asking about individual experiences in general may lack detail, whereas TransLink's method of asking about the previous trip could result in capturing irregular travel, but it is likely negligible compared to those reporting regular travel behavior. In addition, both agencies ask questions regarding travel frequency, making it possible to distinguish frequent vs. infrequent users. Both agencies also assess transit user access to a car. Furthermore, because the questionnaires asked similar as well as several identical 
questions, the differences in the method of the data collection were not problematic for this study; only data that were consistent between the two cities were included.

The STM provided information for a total 18,595 interviews, and TransLink for 42,061 interviews from 2009 to 2013. Not all questions were asked every year, and, therefore, inconsistent survey questions were removed from the database and not included in the analysis. The data were not weighted, as it would require having auxiliary information for all transit users in the regions, and also because the sample did not contain geographic information such as origin and destination points. However, the data are collected by the STM and TransLink in an attempt to collect representative random samples by ensuring that every transit user in each region with phone access has the same chance of being selected to be part of the survey following the basic rules of obtaining a representative random sample (Dunlop and Tamhane 2000).

Additional data cleaning was required to remove entries that were missing relevant information as well as apparent mistakes in the data. The surveys asked information including, but not limited to, transit user socioeconomic status, personal preferences, perception of satisfaction, and travel habits. Information about household structure and the presence of children was not included.

Satisfaction questions were asked using a 10-point Likert scale, and categorical data were converted to a series of dummy variables before being included in the analysis. Tables 1 and 2 list the questions that were used from the surveys from each transit agency. Data were then separated into three modal categories: bus, metro/SkyTrain, and the modes in combination. To clarify, bus users were individuals who reported using only the bus, metro/SkyTrain users were those who traveled only by rail, and individuals who used both modes represent those who reported using both modes in the same trip. The analysis was conducted for every distinct modal category to account for the differences in mode-specific service attributes. After data preparations were completed, a total of 14,842 observations were found suitable for the STM analysis and 29,224 for TransLink. This sample size at the $95 \%$ confidence level represents a confidence interval of $1.8 \%$ for transit users in Montreal and 1.3\% for users in Vancouver. For the STM, the analysis yielded 7,190 bus users, 3,778 metro users, and 3,874 individuals who used both modes in combination. For Translink, the sample included 9,850 bus users, 6,604 SkyTrain users, and 12,770 who used both modes. 
TABLE 1. Factor Loadings: STM, Montreal

\begin{tabular}{|c|c|c|c|}
\hline Survey Questions & Bus & Metro & Both \\
\hline \multicolumn{4}{|l|}{ Car Access } \\
\hline I use public transit because I don't have a car. & -.904 & .882 & -.904 \\
\hline I currently have car access. & .531 & .650 & .547 \\
\hline I use public transit because I don't like driving/traffic. & .551 & & .540 \\
\hline \multicolumn{4}{|l|}{ Financial Situation } \\
\hline My income is greater than $\$ 80,000$. & .664 & .648 & .652 \\
\hline Status = work (compared to student, other) & .747 & .774 & .747 \\
\hline \multicolumn{4}{|l|}{ Life Phase } \\
\hline What is your age? & -.854 & -.810 & -.843 \\
\hline Status = student (compared to work, other) & .882 & .866 & .871 \\
\hline \multicolumn{4}{|l|}{ Travel Day } \\
\hline When during the week do you take the bus most often? (mainly on the weekend) & -.766 & .807 & -.672 \\
\hline When during the week do you take the bus most often? (mainly during the week) & .800 & 790 & .783 \\
\hline \multicolumn{4}{|l|}{ Loyalty } \\
\hline I have been using STM public transit for at least one year as frequently as I do now. & .697 & & \\
\hline I plan to keep using the STM public transit network for a few or many more years. & .810 & .741 & .804 \\
\hline Getting a new job, moving, or having a child would make me use public transit less in the next year. & & -.709 & -.732 \\
\hline \multicolumn{4}{|l|}{ Frequency (Regularity) } \\
\hline I am using STM public transit less than I used to. & -.594 & .692 & -.606 \\
\hline In the last 30 days, what percentage of your trips would you say you made using public transit? & .734 & .763 & .745 \\
\hline How many times did you take transit in the last 30 days? & .734 & .736 & .728 \\
\hline \multicolumn{4}{|l|}{ Convenience } \\
\hline I use public transit because it is punctual/efficient. & .899 & .851 & .914 \\
\hline I use public transit because I don't like driving/traffic. & & -.822 & \\
\hline \multicolumn{4}{|l|}{ Importance Of Low Costs } \\
\hline I use public transit because of the low costs. & .964 & .965 & .961 \\
\hline
\end{tabular}


TABLE 1. (cont'd.) Factor Loadings: STM, Montreal

\begin{tabular}{|c|c|c|c|}
\hline Survey Questions & Bus & Metro & Both \\
\hline \multicolumn{4}{|l|}{ Satisfaction with Services } \\
\hline What is your level of satisfaction with the cleanliness inside the bus/ metro cars? & .518 & .831 & \\
\hline What is your level of satisfaction with the cleanliness inside the metro stations? & & .838 & \\
\hline What is your level of agreement with the statement: "In the last month, the metro service on the lines that I used was reliable." & .518 & .539 & .512 \\
\hline Last month, what was your level of security at any time you were on the bus or in metro installations? & .759 & .541 & .748 \\
\hline What is your level of satisfaction, out of 10, with the way in which drivers start, drive, and stop their buses on the STM bus routes that you use? & .795 & & .830 \\
\hline What is your agreement with the statement: "I feel that the driver drives carefully while respecting traffic regulations." & .822 & & .842 \\
\hline \multicolumn{4}{|l|}{ Satisfaction Cleanliness } \\
\hline What is your level of satisfaction with the cleanliness inside the bus? & & & .592 \\
\hline What is your level of satisfaction with the cleanliness inside the metro stations? & & & .865 \\
\hline What is your level of satisfaction with the cleanliness inside the metro cars? & & & .881 \\
\hline Total variance (\%) & $65 \%$ & $67 \%$ & $68 \%$ \\
\hline
\end{tabular}

*Blanks show that the question had a factor loading of $<0.5$ or that it did not factor with the question group. 
TABLE 2. Factor Loadings: TransLink, Vancouver

\begin{tabular}{|c|c|c|c|}
\hline Survey Questions & Bus & SkyTrain & Both \\
\hline \multicolumn{4}{|l|}{ Car Access } \\
\hline I use public transit because I do not have a car (I have no choice). & -.715 & -.772 & .748 \\
\hline Which of the following best describes your total household income before taxes? (Under $\$ 35,000)$ & -.513 & & \\
\hline I use public transit because parking costs too much. & .666 & .531 & .713 \\
\hline Do you have access to a car, van or truck as a driver or passenger for the trips you make using public transit? Yes & .726 & .715 & .718 \\
\hline \multicolumn{4}{|l|}{ Financial Situation } \\
\hline Which of the following best describes your total household income before taxes? (More than $\$ 75,000$ ) & -.559 & -.781 & 677 \\
\hline Which of the following best describes your total household income before taxes? (Between $\$ 35,000-\$ 75,000$ ) & .920 & & \\
\hline Which of the following best describes your total household income before taxes? (Under $\$ 35,000)$ & & .740 & -.686 \\
\hline \multicolumn{4}{|l|}{ Life Phase } \\
\hline What is your age? & -.821 & .793 & .800 \\
\hline What is the highest level of education you have completed? Some high school or less & .614 & & -.510 \\
\hline What is your present employment status? "Student" & .806 & .807 & -.820 \\
\hline \multicolumn{4}{|l|}{ Travel Day } \\
\hline Did you make your last one way trip on Monday-Friday between 5-9:30am or Monday-Friday between 3-630pm? & -.802 & & -.693 \\
\hline Did you make your last one way trip on Saturday, Sunday or holiday? & .784 & & .809 \\
\hline Did you make your last one way trip on Monday-Friday between 5-9:30am or Monday-Friday between 3-6:30pm? & & .829 & -.712 \\
\hline Did you make your last one way trip on Saturday, Sunday or holiday? & & .835 & .814 \\
\hline \multicolumn{4}{|l|}{ Loyalty } \\
\hline Compared to six months ago, would you say you are now riding transit more regularly, less regularly, or about the same? (Less regularly than 6 months ago) & -.805 & -803 & .789 \\
\hline How likely are you to continue to take transit as often as you do now in the foreseeable future? (Probably or definitely continue as often as I do now) & .697 & .705 & .695 \\
\hline \multicolumn{4}{|l|}{ Frequency (Regularity) } \\
\hline Approximately how long have you been riding transit on a regular basis? (Number of years and months) & .723 & .854 & .743 \\
\hline Regular user (yes/no) & .817 & .817 & .800 \\
\hline \multicolumn{4}{|l|}{ Convenience } \\
\hline I use public transportation because it is reliable and because it has a good schedule. & .674 & .883 & .512 \\
\hline I use public transit because of the convenience of the stops and stations. & .730 & & .761 \\
\hline
\end{tabular}


TABLE 2. (cont'd.) Factor Loadings: TransLink, Vancouver

Survey Questions

\begin{tabular}{l|l|l} 
Bus & Skytrain & Both \\
\hline
\end{tabular}

\section{Low Costs}

I use public transit because it is cheaper.

I use public transit because of the convenience of the stops and stations.

\begin{tabular}{l|l|l|}
.837 & .715 & .853 \\
\hline
\end{tabular}

\section{Satisfaction with Services 1}

How would you rate the bus for having a direct route?

Trip duration from the time you boarded to the time you got off the bus?

How would you rate it in terms of providing on time reliable service?

How would you rate it in terms of frequency of service?

Feeling safe from crime onboard the bus?

How would you rate it for feeling safe from crime at the bus stop or transit exchange where you boarded?

How would you rate it in terms of being clean and graffiti free?

How would you rate that station in terms of safety?

How would you rate your trip in terms of feeling safe from crime onboard SkyTrain?

\section{Satisfaction with Services 2}

Having a courteous bus operator?

How would you rate it in terms on being clean and graffiti free?

How would you rate it for feeling safe from crime at the bus stop or transit exchange where you boarded?

Feeling safe from crime onboard the bus?

How would you rate the bus for having a direct route?

Trip duration from the time you boarded to the time you got off the bus?

How would you rate it in terms of frequency of service?

How would you rate it in terms of providing on time reliable service?

.539

\section{Satisfaction (SkyTrain Only)}

How would you rate it in terms of frequency of service?

How would you rate it in terms of being clean and graffiti free?

How would you rate it in terms of providing on time reliable service?

How would you rate that station?

How would you rate your trip in terms of feeling safe from crime onboard SkyTrain?

\section{Total variance}

*Blanks show that the question had a factor loading of $<0.5$ or that it did not factor with the question group

\begin{tabular}{|l|l|l|}
\hline .676 & & \\
\hline .720 & & \\
\hline .744 & & .694 \\
\hline .797 & & .640 \\
\hline & & .556 \\
\hline & & .599 \\
\hline & & .684 \\
\hline & & .776 \\
\hline
\end{tabular}

\begin{tabular}{|l|l|l|l|}
\hline .561 & & .608 \\
\hline .617 & & .586 \\
\hline .785 & & \\
\hline .830 & & \\
\hline & & .682 \\
\hline & & .752 \\
\hline & & .767 \\
\hline
\end{tabular}

\begin{tabular}{|c|c|c|}
\hline & .727 & \\
\hline & .728 & \\
\hline & .766 & \\
\hline & .786 & \\
\hline & .807 & \\
\hline $64 \%$ & $65 \%$ & $61 \%$ \\
\hline
\end{tabular}




\section{Analysis}

\section{Principal Component Factor Analysis}

Using SPSS 17, principal component analysis (factor analysis) was employed for each modal category to understand how survey questions related to each other. This statistical method considers the complete set of questions from the survey as well as their responses and creates a certain number of groupings (factors) that capture the variability in the data and therefore aids in reducing the number of variables analyzed (Doloreuxa and Shearmur 2013; Krizek and El-Geneidy 2007; Song and Knaap 2007). Using varimax rotation to maximize the variance of the squared loadings and Eigen values greater than one, this type of factor analysis was employed for each modal category within each agency: bus, metro/SkyTrain, and users who combined modes. Tables 1 and 2 demonstrate the results of the principal component analysis for the STM and TransLink and provide the factor loadings for the specific analysis of each modal category. These tables present the variables and corresponding survey questions used to build the components needed for the next phase of analysis. The numbers in the tables indicate the weight of each of the respective components; these factor loadings were grouped together when they were greater than 0.5 or less than -0.5 .

Tables 1 and 2 show that the categories for each of the grouped questions were given titles that could be applied to both the STM and TransLink data, where possible. However, variation in the wording of specific questions was observed even though the questionnaires from both transit agencies assess individual socioeconomic profiles, travel behavior, opinions about transit, and perceived satisfaction of transit. Furthermore, questions that could not be grouped due to statistically insignificant factor loadings were removed from the analysis. The next phase of the analysis used the groups of questions, or factors, to define the market segments present in each transit agency.

\section{K-means Cluster Analysis}

Based on the results of the principal component analyses for each agency, k-means cluster analyses were performed using SPSS 17 with the factors developed for each modal category in both cities. This type of analysis is common in the literature and has proven to be a good method for segmentation (Damant-Sirois et al. 2014; Doloreuxa and Shearmur 2013; Jain 2010; Krizek and El-Geneidy 2007; Song and Knaap 2007). The factor scores that were generated for each variable included in Tables 1 and 2 were grouped together to identify segments of transit users for each modal category in both cities. In other words, the goal of the cluster analysis was to identify different groups of transit users within the existing customer base of the STM and TransLink by grouping riders with similar socioeconomic profiles, personal values, levels of satisfaction, and travel habits. The analysis maximized the differences between groups while minimizing the differences within groups. As the method used is an exploratory form of cluster 
analysis, it was important to set criteria to determine how many clusters to retain. Although there are many approaches to judging the quality of segments (Dibb and Simkin 2010), because this analysis aims to update Krizek and El-Geneidy's (2007) Transit Segmentation Model, we used the transit-specific criteria set by these authors to guide our decision:

- statistical output (cluster characteristics)

- relevance and transferability to transport policy

- previous studies

- common sense and intuition

Clustering was tried with three to eight groups, as suggested by Damant-Sirois et al. (2014), and final clusters of six and seven groups were found to provide the best qualitative descriptions for the groups using different modes in each city (Figures 2 and 3). These clusters are not specific to individual modes and named based on the prevalence of different factors. The sample size of each cluster is included below the name, and the bars represent each of the factors presented in Tables 1 and 2. Positive bar values represent that this factor was positively associated with the cluster, and vice versa. For example, "economizing riders" are labeled as such because they tend to use transit due to the associated cost savings. Although the figures demonstrate that most categories were consistent across modes, some differences exist. For example, Figure 2 shows that for every cluster of bus and bus and metro users, the first bar in every group is colored in light pink and represents access to a car. However, this bar is not included for the metro users; instead, metro user car access is determined by a whitecolored factor, representing that a user does not have access to a car. The reason for the difference between "car access" and "no car access" is due to the results of the factor analysis represented in Table 1. 
BUS USERS

STM CLUSTERS
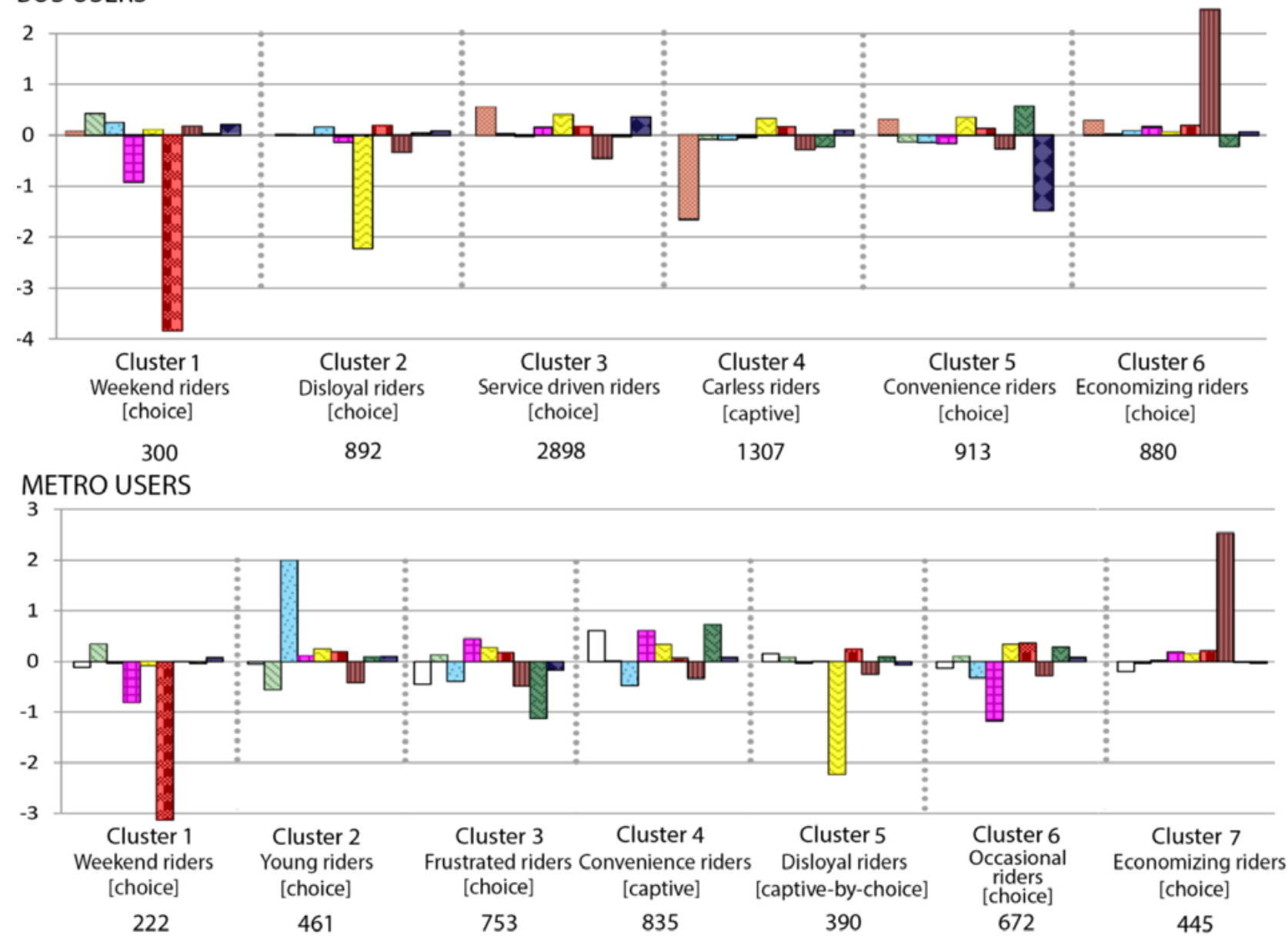

BUS and METRO USERS

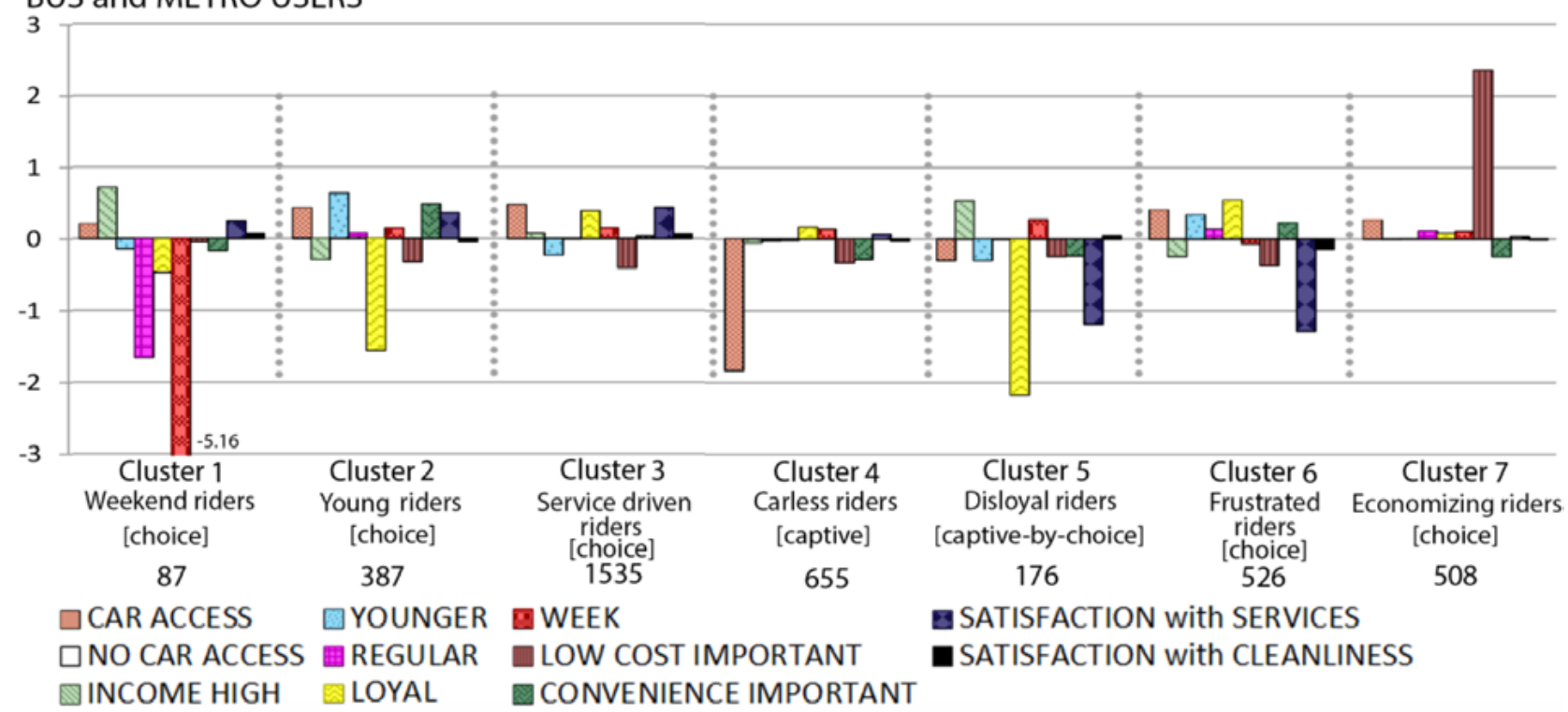

FIGURE 2. K-means cluster analysis for STM 
BUS USERS

TRANSLINK CLUSTERS

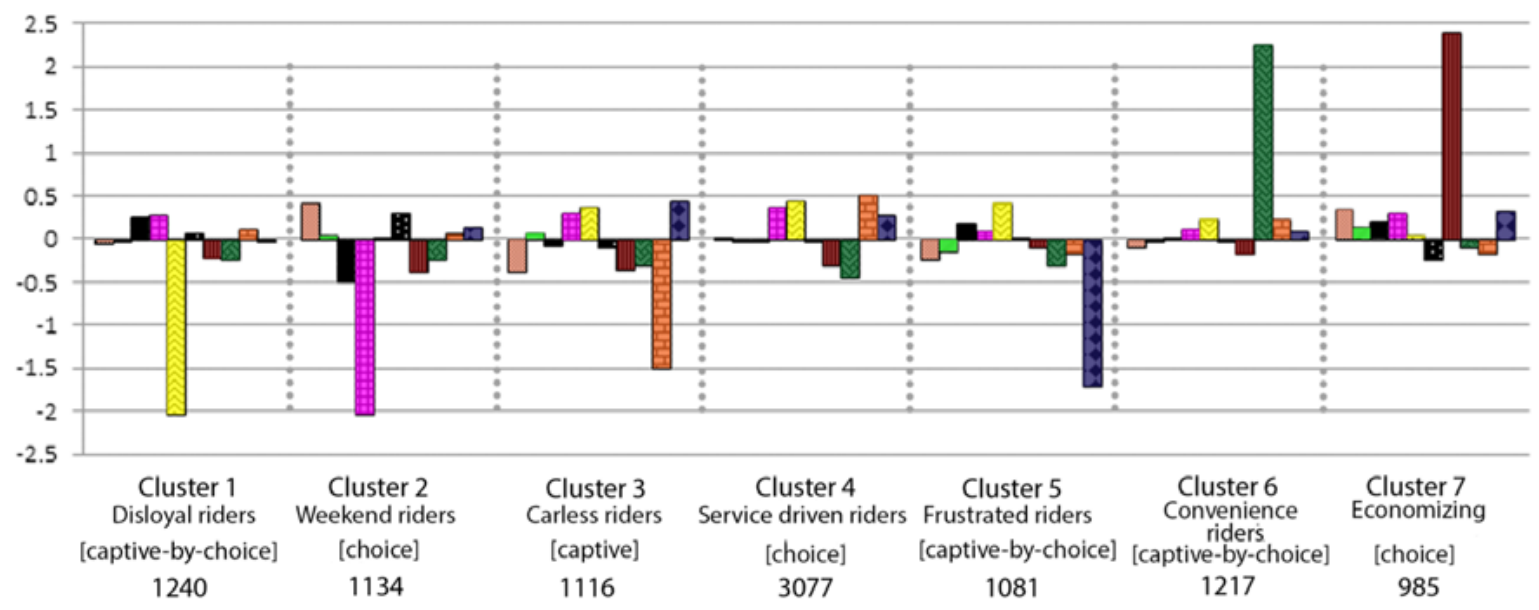

SKYTRAIN USERS

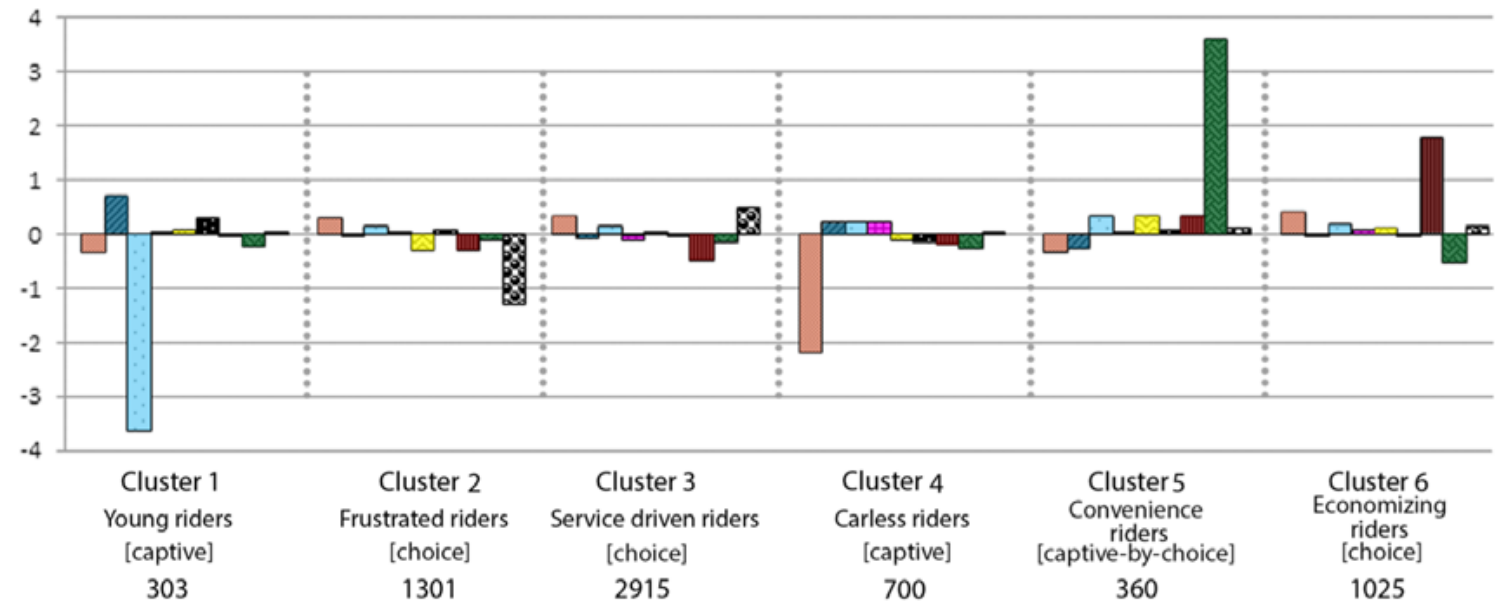

BUS and SKYTRAIN USERS

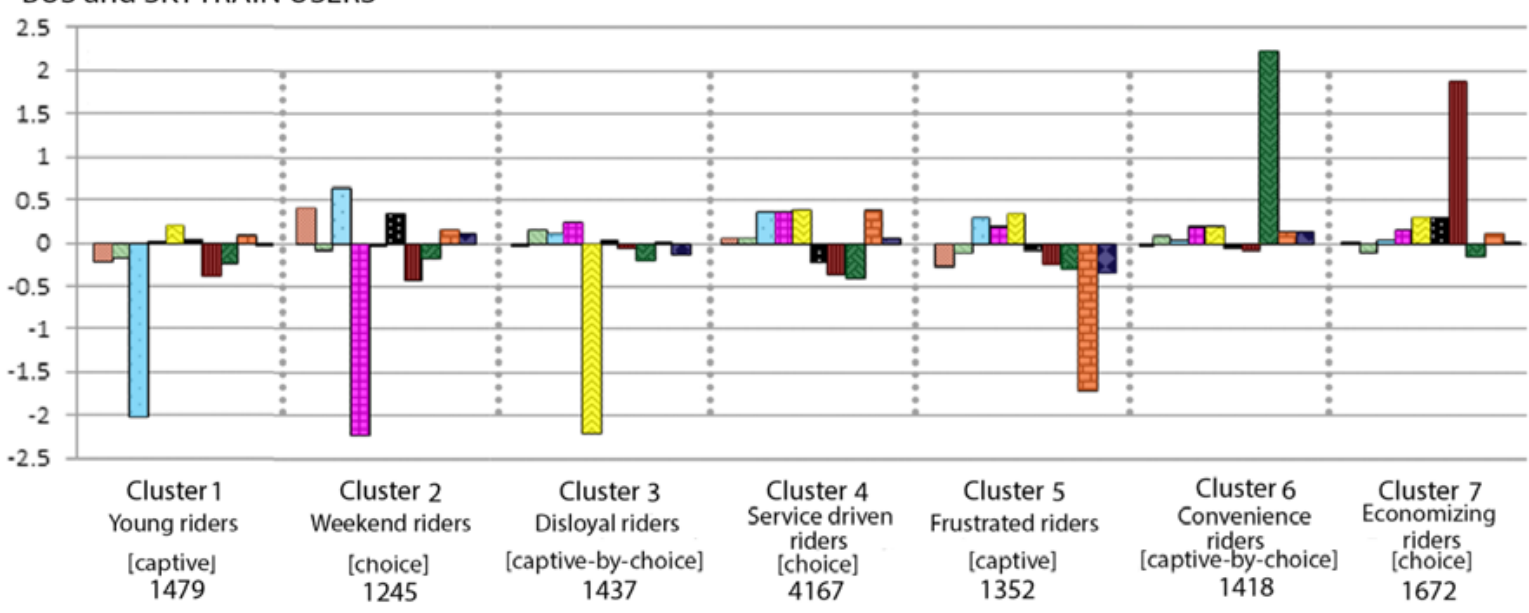

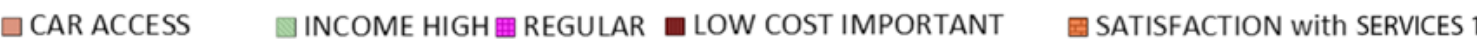
INCOME LOW YYOUNGER IOYAL CONVENIENCE IMPORTANT INCOME MEDIUM OLDER

a WEEKEND SATISFACTION with SERVICES (SKYTRAIN)

FIGURE 3. K-means cluster analysis for TransLink 
Similar to the results of Krizek and El-Geneidy's (2007) segmentation analysis, Figures 2 and 3 demonstrate whether a cluster is categorized as a choice or captive users based on their income and access to a car:

- Choice users: Car access

- Captive users: No car access, low income

However, the results of the present study revealed that the data described more than choice and captive users, identifying a group of transit users present in the two cities that, to our knowledge, has not been previously identified in the literature. This new group was named "captive-by-choice" to reflect that they are captive to transit because they do not have access to a car but likely have chosen this situation, as they appear not to have as much of an income barrier compared to other clusters:

- Captive-by-choice users: No car access, do not have low income

Figures 2 and 3 use the terms "captive," "choice," and "captive-by-choice" to describe the clusters present among all modes. Finally, a description of the results of the cluster analysis is provided in Table 3.

TABLE 3. STM and Translink Clusters

\begin{tabular}{|c|c|c|c|}
\hline Rider Type & Bus Users & Metro/SkyTrain Users & Bus and Metro/SkyTrain Users \\
\hline $\begin{array}{l}\text { Service- } \\
\text { driven riders }\end{array}$ & $\begin{array}{l}\text { Have access to a car, do not have low } \\
\text { incomes, are loyal, and travel during } \\
\text { the week. Are not influenced by cost or } \\
\text { convenience, satisfied with services. }[S, T]\end{array}$ & $\begin{array}{l}\text { Have access to a car, do not have low } \\
\text { incomes, and tend to be loyal. Are older, } \\
\text { use the system occasionally, and are } \\
\text { not influenced by cost or convenience, } \\
\text { satisfied with services. [T] }\end{array}$ & $\begin{array}{l}\text { Have access to a car, tend to be high } \\
\text { income and loyal. Are older users } \\
\text { who travel during the week, are not } \\
\text { motivated by cost savings, and are } \\
\text { satisfied with services. [S,T] }\end{array}$ \\
\hline $\begin{array}{l}\text { Economizing } \\
\text { riders }\end{array}$ & $\begin{array}{l}\text { Have access to a car, do not have a low } \\
\text { income, and regularly commute during } \\
\text { the week. Are largely motivated by cost } \\
\text { savings. [S,T] }\end{array}$ & $\begin{array}{l}\text { Have access to a car and regularly travel } \\
\text { during the week. Tend to be loyal and are } \\
\text { strongly motivated by cost. [S,T] }\end{array}$ & $\begin{array}{l}\text { Have access to a car, and are regular } \\
\text { loyal users who are motivated by } \\
\text { cost savings. }[\mathrm{S}, \mathrm{T}]\end{array}$ \\
\hline $\begin{array}{l}\text { Convenience } \\
\text { riders }\end{array}$ & $\begin{array}{l}\text { Tend to be older, do not have high } \\
\text { incomes, and travel during the week. Are } \\
\text { loyal and very motivated by convenience. } \\
{[S, T]}\end{array}$ & $\begin{array}{l}\text { Are older, loyal, satisfied with services, and } \\
\text { very motivated by convenience. Do not } \\
\text { have access to a car. }[\mathrm{S}, \mathrm{T}]\end{array}$ & $\begin{array}{l}\text { Tend to be older, loyal, satisfied } \\
\text { with services, and motivated by } \\
\text { convenience. Have high incomes and } \\
\text { do not have access to a car. [T] }\end{array}$ \\
\hline $\begin{array}{l}\text { Weekend } \\
\text { riders }\end{array}$ & $\begin{array}{l}\text { Occasional users who primarily take } \\
\text { transit on the weekend, have access to } \\
\text { cars, and tend to be loyal. Are generally } \\
\text { satisfied with services. [S,T] }\end{array}$ & $\begin{array}{l}\text { Occasional users who primarily take } \\
\text { transit on the weekend, have access to } \\
\text { cars, and tend to be loyal. Tend to be } \\
\text { older and high income and are generally } \\
\text { satisfied with services. [S] }\end{array}$ & $\begin{array}{l}\text { Occasional users who primarily } \\
\text { take transit on the weekend. Are } \\
\text { older and satisfied with services, but } \\
\text { are not loyal or motivated by cost } \\
\text { savings or convenience. }[S, T]\end{array}$ \\
\hline $\begin{array}{l}\text { Occasional } \\
\text { weekday } \\
\text { rider }\end{array}$ & & $\begin{array}{l}\text { Occasionally use transit during the week. } \\
\text { Have car access, high incomes, tend to be } \\
\text { older, and are motivated by convenience, } \\
\text { but not by cost savings. Are satisfied with } \\
\text { the services. [S] }\end{array}$ & \\
\hline $\begin{array}{l}\text { Frustrated } \\
\text { riders }\end{array}$ & $\begin{array}{l}\text { Are unsatisfied with transit services, } \\
\text { do not have access to a car, and are not } \\
\text { medium income. Tend to be young and } \\
\text { regular users who are loyal to the system } \\
\text { and are not motivated by cost savings or } \\
\text { convenience. [T] }\end{array}$ & $\begin{array}{l}\text { Are unsatisfied with transit services and } \\
\text { do not use them due to associated cost } \\
\text { savings or convenience. Are older, regular } \\
\text { users who have car access. [S,T] }\end{array}$ & $\begin{array}{l}\text { Are unsatisfied with services and not } \\
\text { motivated by cost savings. Are low- } \\
\text { income, older, regular users who are } \\
\text { loyal to the system. [S,T] }\end{array}$ \\
\hline
\end{tabular}


TABLE 3. (cont'd.) STM and Translink Clusters

\begin{tabular}{|l|l|l|l|}
\hline \multicolumn{1}{|c|}{ Rider Type } & \multicolumn{1}{|c|}{ Bus Users } & \multicolumn{1}{c|}{ Metro/SkyTrain Users } & \multicolumn{1}{c|}{ Bus and Metro/SkyTrain Users } \\
\hline $\begin{array}{l}\text { Disloyal } \\
\text { riders }\end{array}$ & $\begin{array}{l}\text { Are not loyal to the system, even though } \\
\text { they do not have access to a car. Tend to } \\
\text { be younger, do not have low incomes, and } \\
\text { are not motivated by cost savings. Are } \\
\text { somewhat satisfied with services. [S,T] }\end{array}$ & $\begin{array}{l}\text { Are not loyal to the system and do not } \\
\text { have access to a car. Use transit during } \\
\text { the week, are not motivated by cost } \\
\text { savings, but are slightly motivated by the } \\
\text { convenience of transit. [S] }\end{array}$ & $\begin{array}{l}\text { Are not loyal to the system and } \\
\text { do not have access to a car. Are } \\
\text { not motivated by cost savings or } \\
\text { convenience, tend to be older, have } \\
\text { higher incomes. [S,T] }\end{array}$ \\
\hline Young riders & & $\begin{array}{l}\text { Tend to be younger and have lower } \\
\text { incomes. Are loyal, use transit regularly, } \\
\text { and are not motivated by cost savings. are } \\
\text { somewhat satisfied with services. [S,T] }\end{array}$ & $\begin{array}{l}\text { Tend to be younger and have lower } \\
\text { incomes. Are loyal, use transit } \\
\text { regularly, and are not motivated by } \\
\text { cost savings. Do not have access to a } \\
\text { car and are somewhat satisfied with } \\
\text { services. [S,T] }\end{array}$ \\
\hline $\begin{array}{l}\text { Carless } \\
\text { riders }\end{array}$ & $\begin{array}{l}\text { Do not have access to a car, do not have } \\
\text { high incomes, and tend to be loyal to } \\
\text { transit. Are older, travel during the week, } \\
\text { and are somewhat satisfied with services. } \\
{[S, T]}\end{array}$ & $\begin{array}{l}\text { Do not have access to a car, do not have } \\
\text { high incomes, and are regular users who } \\
\text { travel during the week. Are not motivated } \\
\text { by cost or convenience, only somewhat } \\
\text { satisfied with services. [T] }\end{array}$ & $\begin{array}{l}\text { Do not have access to a car, do not } \\
\text { have high incomes, and tend to be } \\
\text { loyal to transit. Are regular users who } \\
\text { are not motivated by cost savings or } \\
\text { convenience. [S] }\end{array}$ \\
\hline
\end{tabular}

$\mathrm{S}=\mathrm{STM}, T=$ TransLink

\section{Discussion}

Based on the findings from the cluster analyses presented in Figures 1 and 2, we were able to update Krizek and El-Geneidy's (2007) transit market segmentation model to account for the different types of transit users that have been identified in the present study. Figure 4, accordingly, demonstrates that choice and captive users are not always separate entities, but instead overlap, showing that some individuals, in fact, chose to be captive.

FIGURE 4.

Krizek and

El-Geneidy's

and the new

conceptual transit segmentation model

of users

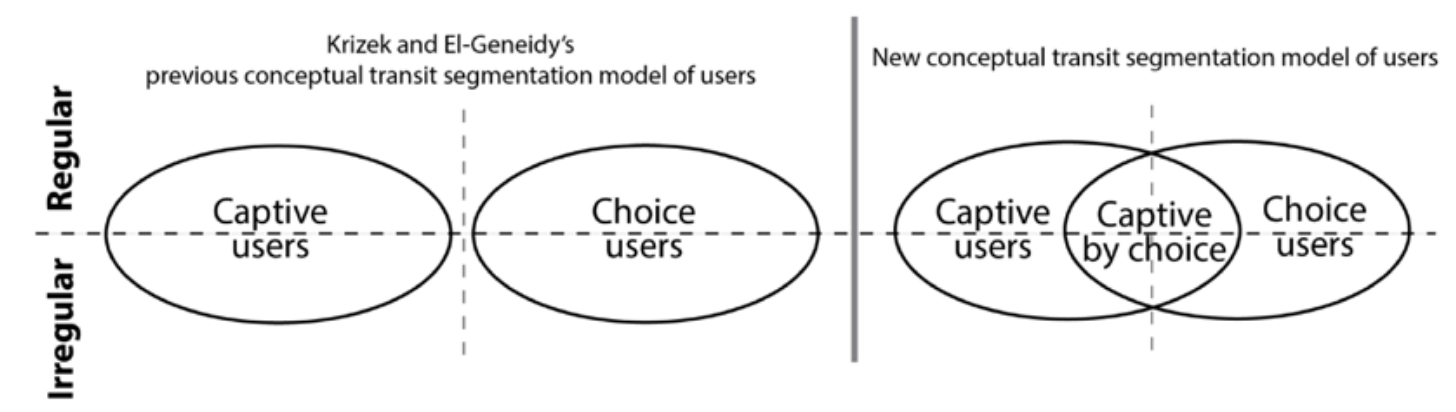

The group that is captive-by-choice may have the financial ability to access another mode, but might have chosen to give up their cars because they prefer the experience of taking transit over that of driving. However, it is important to recognize that because information on household structure is not available to include in the analysis, individuals living in larger households have a higher chance of being financiallyconstrained compared to those in the same income bracket living with fewer family members. Therefore, some captive-by-choice users who have many members in their household may be more financially-constrained compared to captive-by-choice users 
who are financially-responsible for fewer household members. Similarly, not all choice riders will have the same transportation options available to them, and some, regardless of choice, may be more restricted to using public transit than others. Nevertheless, Figure 4 demonstrates that given these findings, the conceptual model makes clear that different groups of people can be accounted for within the broader categories of captive, choice, and captive-by-choice.

\section{A New Conceptual Transit Segmentation Model}

The new model presented in Figure 5 could serve as a tool for transit agencies wishing to develop marketing strategies to increase satisfaction and loyalty among many users. More specifically, this broader segmentation strategy can be used as a framework to better understand the urgency of developing policy interventions geared at the different groups using transit. Figure 5 adds to the new transit market segmentation model by taking it one step further to demonstrate the predictability of future usage of the different groups:

FIGURE 5.

Predictability of transit usage

by group

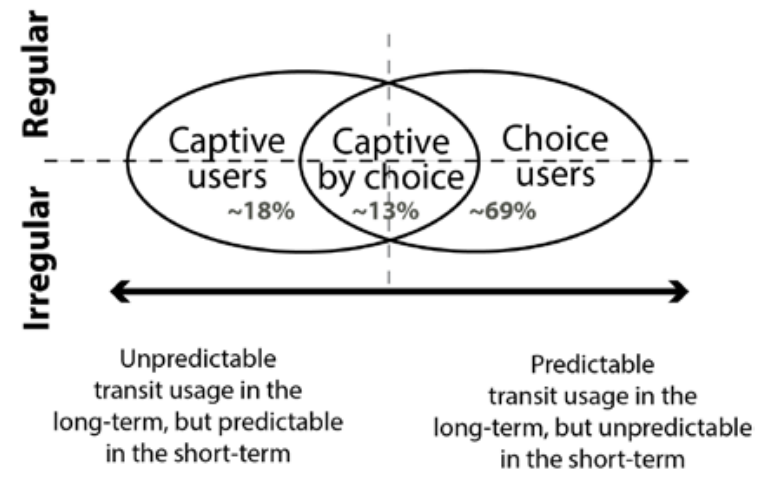

Figure 5 demonstrates that whereas choice users are likely to continue using transit in the long term, they may not choose to use it for all trips in the short term, as they have alternative modes available to them. Captive users, however, do not have access to alternative modes and, therefore, in the short term are predicted to use transit, but in the long term might gain access to a car or increase their income and, consequently, become captive-by-choice or choice users. Therefore, while at any given point it is likely that there will always be captive users, choice users, and captive-by-choice users, individuals will likely move between categories throughout the course of their lives. The goal of transit agencies should be to maximize the number of choice riders in a city while also working to better serve captive and captive-by-choice riders who have fewer modal options and, therefore, may also have more limited access to opportunities. The following paragraphs provide specific policy interventions aimed at inspiring users in different categories to continue using transit as they go through different life phases. 


\section{Choice Users ( 69\%)}

In Vancouver and Montreal, choice users make up the majority of the transit market, and, therefore, it is important to motivate these users to continue using transit in the future. Service-driven riders represent the largest group, and, therefore, their needs should be prioritized. Economizing riders, however, represent another large group of transit users, and policies should be carefully developed to encourage this group to continue using transit. However, the needs and desires of weekend riders and occasional riders should not be overlooked, as service improvements geared specifically at this group may result in increased usage.

Service-driven riders often use transit because they are satisfied with the services and with the characteristics associated with their trips. To motivate these users to continue using transit, agencies should focus on maintaining the cleanliness and the safety of services (de Oñaet al. 2013; Weinstein 2000), develop service improvements such as real-time travel information, and communicate transit investment and plans for service improvements (dell'Olio et al. 2011; Tyrinopoulos and Antoniou 2008).

Economizing riders often use transit because they benefit from the associated cost savings. Providing a low-cost transit service is associated with ridership (D'Alessandro and Des 2008; Hodge et al. 1994), and to positively impact individual perception of service and ultimately motivate their loyalty, transit agencies should communicate the cost saving benefits associated with using transit compared to other modes (Lai and Chen 2011). Agencies would also benefit from developing policies that encourage ridership through financial motivation (such as reduced fares). Increases in fares will likely have a negative influence on this group's transit ridership and, therefore, must be carefully planned. Finally, cities can help motivate this group to continue using transit by developing policies that increase the price of driving and parking cars.

Weekend riders and occasional riders are grouped together, as they represent irregular users. Transit agencies should ensure that these users develop a positive perception of the system with regard to efficiency, travel time, and reliability (Carreira et al. 2014; Chou et al. 2014; de Oña et al. 2013). In the long term, transit agencies should focus on improving the common negative cultural image that is often attributed to transit (Schweitzer 2014). Transit's cultural stigma can be changed by the implementation of policies that promote the service as being more comfortable and more efficient than using a private motorized vehicle (Chou and Kim 2009; Chou et al. 2014; Lee et al. 2009). Individual attitudes and preconceived ideas about public transit can be improved through policies that promote the aspects of transit that are unique to the service such as the ability for commuters to save time by working, reading, using the internet, or relaxing while they travel (Cain et al. 2009).

Although not all frustrated riders are choice riders, the majority fit into this overarching category. They are regular users who are not motivated by cost savings and are not satisfied with the services provided by public transit agencies. To satisfy these users, transit agencies should ensure that the system is clean, safe, and reliable (Burkhardt 2003; de Oña et al. 2013; Susilo and Cats 2014; Weinstein 2000). Additionally, these riders 
would benefit from the implementation of an advanced information system to better communicate waiting times (Politis et al.2010), route information, and connections to alternative modes such as bicycle share to increase the ease of usage of the entire transit system. Finally, it is important to note that although these riders have been categorized as choice riders, they may not have as many options as other choice riders, and therefore, although not low-income and having access to a car, could be restricted to using public transit. This is an area of research that should be explored in the future.

\section{Captive Users ( 18\%)}

Captive users are often carless riders and young riders, and transit agencies should take special care to cater to the needs of these groups to increase rider satisfaction in the present and not lose them in the future. Life-cycle changes (e.g., student to employment, renting to home-ownership, changes in family size and structure, etc.) often result in travel behavior changes (Evans 2004; Grimsrud and El-Geneidy 2014; Perk et al. 2008). Therefore, if captive users are not satisfied with the services provided by the transit agency, they may consider switching their mode when they increase their income due to a change in employment.

Carless riders use transit because they do not have access to a vehicle and do not have high incomes. Transit agencies must assess the needs and desires of this group and engage in equitable planning that recognizes that this group is strongly reliant on public transit (Stanley and Lucas 2008). In addition, transit agencies should provide the safest services possible for this group, as they do not have alternative options; depending on the context, safety provisions may include the installation of platform screen doors, additional lighting or surveillance cameras, and even security guards.

Although not all young riders are captive, this group tends to take transit because of their low incomes. Transit agencies should aim to improve how young transit users experience transit by developing technologically-current online customer feedback tools such as social media, web-based forums, and customer information mobile applications that can provide useful information for riders (Ferris et al. 2010). Furthermore, in the long term, agencies should be prepared to accommodate these uses as they go through lifestyle changes. This may include increasing convenience by increasing spatial and temporal coverage density.

\section{Captive-by-Choice Users ( 13\%)}

The identification of the captive-by-choice segment provides an important conceptual step from the car-as-norm paradigm that is often dominating transport research and policy. This newly-identified group appears to view public transit neither as a last resort when no options are available nor a mere complement to other transport modes. Alternatively, the existence of this group suggests that these users view transit as a viable transportation alternative on its own; in Vancouver and Montreal, it includes convenience riders and disloyal riders. Because these groups are likely to have the financial accessibility to switch modes, it is in the best interest of transit agencies 
to develop a transit system that takes into account the needs and desires of these users. For example, for captive-by-choice users, public transit is likely to be in direct competition with car-share programs such as $\mathrm{Car} 2 \mathrm{Go}$ and ride-share services and Transportation Network Companies (TNCs) such as Uber and the lower-cost UberX (Car2Go 2015; Rayle et al. 2014; Uber 2015).

Convenience riders generally take transit because they benefit from the convenience of this mode compared to other modes. Well-integrated services provided at and around transit stations are likely to attract these users. For example, in many regions, free wi-f is now offered on trains and buses as well as stations to provide an additional service that appeals to younger generations. Such improvements are likely to increase overall levels of satisfaction for all users and attract irregular commuters to begin enjoying commuting by transit regularly. Furthermore, transit users tend to have a biased, distorted perception regarding transit travel time and waiting time, and they often report travel and waiting times that are longer than reality (Diab and El-Geneidy 2014). Correcting this distortion by using polices that improve the awareness of transit service qualities, as well as by implementing technologies such as next-arrival services, may help in increasing transit use (Garvill et al. 2003; Kenyon and Lyons 2003; Mishalani et al. 2006; Rose and Ampt 2001).

To increase loyalty among disloyal riders, transit agencies should communicate the benefits of using transit to these groups and focus on maintaining a safe, clean, and convenient system (Figler et al. 2011; Lai and Chen 2011; Minser and Webb 2010). However, transit agencies should also invest in better understanding the specific needs and desires of this group, as it is not clearly understood why these users are strongly disloyal.

\section{Conclusion}

This cluster analysis of two Canadian transit agencies links customer points of view to transit performance to bridge an existing gap in public transit segmentation research. The analysis has made clear that although different segments exist within each modal category, the overarching categories of captive, choice, and captive-by-choice are helpful to develop policy recommendations that reach further than policies directed at a single cluster. Because the findings are consistent in both the geographically-distinct settings of Montreal and Vancouver, this research is expected to be replicable and applicable in other cities. However, future research would benefit from applying and testing a similar segmentation analysis in other cities, especially in the US, where transit mode shares tend to be lower and the percentage of captive riders tends to be higher. Furthermore, although choice, captive, and captive-by-choice users are expected to be present in all transit markets, the percentage of users per group is expected to vary depending on the context. System improvements that are targeted at a specific segment could improve the experience of other groups as well, thereby motivate ridership among different users. 
In addition to the findings of the analysis, this paper has also demonstrated how existing data from transit agencies can be used productively to inform public transit research, policy, and managerial practice. In the future, to further help in the development of policies that aim to retain and/or increase transit ridership, research should include in-depth analyses focused on understanding the needs and desires of the different market segments and set out to better understand how to motivate non-users to use public transit.

\section{Acknowledgment}

The authors thank Brigitte Vallée and Isabelle Ouellet from the STM and Victor Gaspar from TransLink for providing access to their customer service questionnaire databases. We also thank the three reviewers for their feedback on the earlier version of the manuscript. This research is funded by the Natural Science and Engineering Research Council (NSERC) and the Social Sciences and Humanities Research Council (SSHRC) of Canada. The ideas and findings presented in this paper represent the authors' views in an academic exercise.

\section{References}

Abou-Zeid, M., R. Witter, M. Bierlaire, V. Kaufmann, and M. Ben-Akiva. 2012. "Happiness and Travel Mode Switching: Findings from a Swiss Public Transportation Experiment." Transport Policy, 19(1): 93-104.

Anable, J. 2005. "Complacent Car Addicts or Aspiring Environmentalists? Identifying Travel Behaviour Segments Using Attitude Theory." Transport Policy, 12(1): 65-78.

Beimborn, E., M. Greenwald, and X. Jin. 2003. "Accessibility, Connectivity, and Captivity: Impacts on Transit Choice. Transportation Research Record, 1835: 1-9.

Beirão, G., and Cabral, J. 2008. Market segmentation analysis using attitudes toward transportation: Exploring the differences between men and women. Transportation Research Record, 2067: 56-64.

Burkhardt, J. 2003. "Critical Measures of Transit Service Quality in the Eyes of Older Travelers." Transportation Research Record, 1835: 84-92.

Cain, A., J. Flynn, M. McCourt, and T. Reyes. 2009. "Quantifying the Importance of Image and Perception to Bus Rapid Transit." National Bus Rapid Transit Institute, University of South Florida.

Car2Go. 2015. www.car2go.com.

Carreira, R., L. Patrício, J. Natal, and C. Magee. 2014. “Understanding the Travel Experience and Its Impact on Attitudes, Emotions and Loyalty Towards the Transportation Provider-A Quantitative Study with Mid-Distance Bus Trips." Transport Policy, 3(1): 35-46. 
Chou, J., and Kim, C. 2009. "A Structural Equation Analysis of the QSL Relationship with Passenger Riding Experience on High Speed Rail: An Empirical Study of Taiwan and Korea." Expert Systems with Applications, 36(3): 6945-6955.

Chou, P., C. Lu, and Y. Chang. 2014. "Effects of Service Quality and Customer Satisfaction on Customer Loyalty in High-Speed Rail Services in Taiwan." Transportmetrica, 10: 915-945.

Curtis, C., and P. Headicar. 1997. Targeting Travel Awareness Campaigns: Which Individuals are More Likely to Switch from Car to Other Transport for the Journey to Work? Transport Policy, 4(1): 57-65.

D'Alessandro, A., and M. Des. 2008. "Fare-Free Transit-A Strategy for Sustainable Transportation." Paper presented at the 2008 Annual Conference of the Transportation Association of Canada.

Damant-Sirois, G., M. Grimsrud, and A/ El-Geneidy. 2014. "What's Your Type: A Multidimensional Cyclist Typology. Transportation, 41(6): 1153-1169.

de Oña, J., R. de Oña, L. Eboli, and G. Mazzulla. 2013. "Perceived Service Quality in Bus Transit Service: A Structural Equation Approach. Transport Policy, 29: 219-226.

dell'Olio, L., A. Ibeas, and P. Cecín. 2011. “The Quality of Service Desired by Public Transport Users." Transport Policy, 18(1): 217-227.

Demby, E. 1994. "Psychographics Revisited: The Birth of a Technique." Marketing Research, 6: 26-26.

Diab, E., and A. El-Geneidy. 2014. "Transitory Optimism: Changes in Passenger Perception Following Bus Service Improvement Over Time." Transportation Research Record, 2415: 97-106.

Dibb, S., and L. Simkin. 2010. "Judging the Quality of Customer Segments: Segmentation Effectiveness." Journal of Strategic Marketing, 182: 113-131.

Doloreuxa, D., and R. Shearmur. 2013." Innovation Strategies: Are Knowledge-Intensive Business Services Just Another Source of Information?" Industry and Innovation, 20(8): 719-738.

Dunlop, D., and A. Tamhane. 2000. Statistics and Data Analysis: From Elementary to Intermediate. Prentice Hall, Upper Saddle River, NJ.

Evans, J. 2004. "Transit Scheduling and Frequency: In Traveler Response to Transportation System Changes." Washington DC: Transportation Research Board.

Ferris, B., K. Watkins, and A. Borning. 2010. "OneBusAway: A Transit Traveler Information System." Mobile Computing, Applications, and Services: 92-106.

Figler, S., P. Sriraj, E. Welch, and N. Yavuz. 2011. "Customer Loyalty and Chicago, Illinois, Transit Authority Buses: Results from 2008 Customer Satisfaction Survey." Transportation Research Record, 2216: 148-156.

Garvill, J., A. Marell, and A. Nordlund. 2003. "Effects of Increased Awareness on Choice Of Travel Mode." Transportation, 30(1): 63-79. 
Grimsrud, M., and A. El-Geneidy. 2014. "Transit to Eternal Youth: Lifecycle and Generational Trends in Greater Montreal Public Transport Mode Share." Transportation, 41(1): 1-19.

Hodge, D., J. Orrell III, and T. Strauss. 1994. "Fare-Free Policy: Costs, Impacts on Transit Service, and Attainment of Transit System Goals." Washington State Department of Transportation. Report Number WA-RD, 277.

Jacques, C., K. Manaugh, and A. El-Geneidy. 2013. "Rescuing the Captive [Mode] User: An Alternative Approach to Transport Market Segmentation." Transportation, 40(3): 625-645.

Jain, A. 2010. "Data Clustering: 50 Years beyond K-means." Pattern Recognition Letters, 31(8): 651-666.

Jensen, M. 1999. "Passion and Heart in Transport-A Sociological Analysis on Transport Behaviour." Transport Policy, 6(1): 19-33.

Kenyon, S., and G. Lyons. 2003. "The Value of Integrated Multimodal Traveller Information and Its Potential Contribution to Modal Change." Transportation Research Part F: Traffic Psychology and Behaviour, 6(1): 1-21.

Krizek, K., and A. El-Geneidy. 2007. "Segmenting Preferences and Habits of Transit Users and Non-Users." Journal of Public Transportation, 10(3): 71.

Lai, W., and C. Chen. 2011. "Behavioral Intentions of Public Transit Passengers-The Roles of Service Quality, Perceived Value, Satisfaction and Involvement.: Transport Policy, 18(2): 318-325.

Lee, J., Jin, B., and Y. Ji. 2009. “Development of a Structural Equation Model for Ride Comfort of the Korean High-Speed Railway." International Journal of Industrial Ergonomics, 39(1): 7-14.

McLaughlin, J., and D. Boyle. 1997. "Transit Incentive Program for Transit-Dependent Riders." Transportation Research Record, 1604: 139-145.

Minser, J., and V. Webb. 2010. "Quantifying the Benefits: Application of Customer Loyalty Modeling in Public Transportation Context." Transportation Research Record, 2144: 111-120.

Mishalani, R., M. McCord, and J. Wirtz. 2006. "Passenger Wait Time Perceptions at Bus Stops: Empirical Results and Impact on Evaluating Real-Time Bus Arrival Information." Journal of Public Transportation, 9(2): 89-106.

Molander, S., M. Fellesson, M. Friman, and P. Skålén. 2012. "Market Orientation in Public Transport Research-A Review." Transport Reviews, 32(2): 155-180.

Palmer, R., and P. Millier. 2004. "Segmentation: Identification, Intuition, and Implementation." Industrial Marketing Management, 33(8): 779-785.

Perk, V., J. Flynn, and J. Volinski. 2008. “Transit Ridership, Reliability and Retention.” National Center for Transit Research. 
Peter, J., and J. Olson. 1999. Consumer Behavior and Marketing Strategy, Eighth Ed. McGraw-Hill, London.

Politis, I., P. Papaioannou, S. Basbas, and N. Dimitriadis. 2010. "Evaluation of a Bus Passenger Information System from the Users' Point of View in the City of Thessaloniki, Greece." Research in Transportation Economics, 29(1): 249-255.

Rayle, L., S. Shaheen, N. Chan, D. Dai, and R. Cervero. 2014. “App-based, On-demand Ride Services: Comparing Taxi and Ridesourcing Trips and User Characteristics in San Francisco. San Francisco, UCTC-FR-2014-08.

Rose, G., and E. Ampt. 2001. "Travel Blending: An Australian Travel Awareness Initiative." Transportation Research Part D: Transport and Environment, 6(2): 95-110.

Schweitzer, L. 2014. "Planning and Social Media: A Case Study of Public Transit and Stigma on Twitter." Journal of the American Planning Association, 80(3): 218-238.

Song, Y., and G.-J. Knaap. 2007. "Quantitative Classification of Neighbourhoods: The Neighbourhoods of New Single-Family Homes in the Portland Metropolitan Area." Journal of Urban Design, 12(1): 1-24.

Stanley, J., and K. Lucas. 2008. "Social Exclusion: What Can Public Transport Offer?" Research in Transportation Economics, 22(1): 36-40.

Statistics Canada. 2014. Focus on Geography Series, 2011 Census.

Susilo, Y., and O. Cats. 2014. "Exploring Key Determinants of Travel Satisfaction for Multi-Modal Trips by Different Traveler Groups." Transportation Research Part A: Policy and Practice, 67: 366-380.

Transportation Research Board. 1998a. A Handbook: Integrating Market Research into Transit Management, 37. Washington, DC: Transportation Research Board.

Transportation Research Board. 1998b. A Handbook: Using Market Segmentation to Increase Transit Ridership, 36. Washington, DC: Transportation Research Board.

Transportation Research Board. 1999. A Handbook for Measuring Customer Satisfaction and Service Quality, 47. Washington, DC: Transportation Research Board.

Tyrinopoulos, Y., and C. Antoniou. 2008. "Public Transit User Satisfaction: Variability and Policy Implications. Transport Policy, 15(4): 260-272.

Uber. 2015. www.uber.com.

Weinstein, A. 2000. "Customer Satisfaction among Transit Riders: How Customers Rank the Relative Importance of Various Service Attributes." Transportation Research Record, 1735: 123-132.

Weinstein, A. 2004. Handbook of Market Segmentation: Strategic Targeting for Business and Technology Firms. Routledge.

Wilson, F., A. Stevens, and J. Robinson. 1984. "Identifying Mode Choice Constrained Urban Travel Market Segments." Canadian Journal of Civil Engineering, 11(4): 924932. 


\section{About the Authors}

DeA VAN LIerop (dea.vanlierop@mcgill.ca) is a Ph.D. Candidate in the School of Urban Planning at McGill University in Montreal. Her research interests include public transit satisfaction and loyalty, land use and transportation planning, pedestrian and cyclist safety, and innovations in transit-oriented development.

Ahmed EL-Geneidy (ahmed.elgeneidy@mcgill.ca) is an Associate Professor at McGill University in Quebec, Canada. His research interests include land use and transportation planning, transit operations and planning, travel behavior analysis including both motorized (auto and transit) and non-motorized (bicycle and pedestrian) modes of transportation, travel behavior of disadvantaged populations (seniors and people with disabilities), and measurements of accessibility and mobility in urban contexts. 